licensing of psychotherapists arose from complaints from his constituents. Although his Bill had met with predictable failure in 1980 , he felt that the National Register began to address the issues which he had raised in Parliament. Mr Timothy Yeo, MP, Parliamentary Under Secretary of State for Health, said that the introduction of the Register could hardly have been more timely. Reports of sexual misconduct by therapists provided a powerful stimulus for regulation of psychotherapists. Although demands had come from some quarters for statutory regulation, he was satisfied that self regulation by the profession was the best way to deal with the complex diversity of psychotherapists who are in practice in the UK. He said that his Department was committed to continue in their supportive role, and other speakers were warmly enthusiastic about the support which had been received from Department of Health officials in establishing the Register.

Dr Michael Pokorny, Chair of the new Registration Board, said that the National Register was a standard bearer in Europe. The structure had already been copied in Ireland and Spain. He stressed the importance of a registration system as barriers between European countries devolve. The National Register lists the names of therapists who have met the training requirements of member organisations. It currently consists of 71 organisations. Each of these organisations has at least 50 members. In deciding whether to admit an organisation to the Registry, some of the prime concerns of the UKCP are the quality of training which the organisations offer their members, and the size of these organisations. The training should be at postgraduate level, and roughly equivalent to MSc standard. Forty organisations which applied to join the Register were judged not to be up to standard. One member of the organisation has already been ejected from the Register because of concerns about standards. The Directory of Member Organisations contains an extraordinary diversity of psychotherapy groups, from the more conventional psychodynamic and cognitive-behavioural groups to Buddist-oriented psychotherapy, hypnotherapy, psychosynthesis and holistic therapies.

Initial funding for setting up the Register came from the Artemis Trust. However, continued funding comes from the constituent members of the organisation. Each organisation pays an annual fee of $£ 650$, but the plan is for these expenses to devolve to individual psychotherapists, who will pay $£ 20$ per annum. For this, they will get a Certificate of Registration.

Medical doctors have had their own registration body in the UK for more than 150 years. The development of a National Register for Psychotherapists represents an important step in the establishment of the profession, and should prove to be a significant advance in monitoring of standards, and enforcement of explicit ethical guidelines. The UKCP's Directory of Member Organisations is a very informative list of the organisations which have met the registration criteria, and provides additional information on each organisation's training requirements and contact addresses. Further information can be obtained from the UKCP, Regents College, Regents Park, London NW1 4MS (telephone 071487 7554).

\title{
Guidelines for the prevention and treatment of benzodiazepine dependence*
}

\author{
RICHARD PETHER, Senior Registrar, Department of Psychiatry, The Royal London \\ Hospital, Whitechapel, London E1 1BB
}

The Substance Misuse Committee of the Mental Health Foundation has produced a booklet called Guidelines for the Prevention and Treatment of Benzodiazepine Dependence. The problem addressed is twofold: encouraging and managing withdrawal, and preventing new cases of dependence. There is no room for complacency because although prescrip-

*The Mental Health Foundation - Press Briefing, 27 May 1993. tions for anxiolytics have halved over the past ten years, prescriptions for hypnotics are unchanged now twice the number for anxiolytics. The average GP can expect to have about 50 long-term benzodiazepine users on his or her list. The long-term safety of these drugs is uncertain and there are side effects, e.g. memory impairment, ataxia and falls in the elderly, and road traffic accidents.

The guidelines are aimed at primary care, where the potential for reducing prescribing is greatest and 
where most people with benzodiazepine dependence will be treated. Emphasis is placed on all staff, including practice nurses, health visitors, and pharmacists, playing a part in the prevention and management of benzodiazepine dependence. The establishment of a 'practice prescribing policy' for the use of benzodiazepines is suggested, and this should also include education of patients, and a commitment to offering a withdrawal programme to long term users.

The booklet is clearly written, with practical advice, and useful summaries of the main points. It contains a brief outline of treatments for anxiety and descriptions of good practice in prescribing benzodiazepines and the management of withdrawal. The main indication for starting benzodiazepines is the short-term (maximum four weeks) relief of severely distressing or disabling anxiety while other treatments are implemented. Discussion with the patient of the need to discontinue benzodiazepine treatment early should take place before initiating treatment. With long-term users the need for negotiation and careful assessment and planning before starting a gradual withdrawal is emphasised. The point is also made that "minimal intervention", such as a recommendation to cut down tranquilliser use and the offer of support, is effective in a significant number of cases. Doctors may overestimate the problems of withdrawal-in fact withdrawal symptoms affect less than half of long-term users.

In the discussion at the briefing it was questioned whether prescribing habits will alter significantly without some form of coercion (e.g. the threat of litigation) but these guidelines represent the view that education is the preferred route to change. They are to be distributed to all general practitioners and are available free of charge from the Mental Health Foundation. A summary of the guidelines is due to appear in the Drug and Therapeutics Bulletin.

\section{An open letter to the Executive Editor of the British National Formulary}

In the preface to the BNF you state that "comments and constructive criticism will be welcome". I should like to ask a question. I should like to know how members of the Committee reach a decision on what dose should be considered the upper limit of medication, and in particular psychotropic medication, commonly known as "the BNF maximum".

As an example, I wish to ask about the depot antipsychotic preparations, fluphenazine decanoate Modecate, and flupenthixol decanoate-Depixol. The recommended test dose for each is Modecate $12.5 \mathrm{mg}$ and Depixol $20 \mathrm{mg}$; the recommended starting dose is Modecate $25 \mathrm{mg}$ and Depixol $40 \mathrm{mg}$. Why then should "the BNF maximum" for Modecate be $50 \mathrm{mg}$ per week but for Depixol $400 \mathrm{mg}$ per week? Why is the "maximum" for one twice the starting dose, and for the other ten times the starting dose?

Looking through the ABPI Data Sheet Compendium, I note that for Modecate, the manufacturers state that "most patients are successfully maintained with the dose range $0.5 \mathrm{ml}$ to $4 \mathrm{ml}(12.5 \mathrm{mg}$ to $100 \mathrm{mg}$ ) given at a dose interval of two to five weeks". For Depixol, on the other hand, the drug company states that "some patients may require up to $400 \mathrm{mg}$ weekly". Is this the basis on which "the BNF maximum" dose is calculated?

I ask for a simple reason. All of my patients are legally detained in hospital. Many of them become well after a slow and cautious increase in dose, but often end up at a level above "the BNF maximum". Typically at that point they consider they have recovered and request to stop medication. At that stage they have a second opinion from the Second Opinion Approved Doctor from the Mental Health Act Commission. Not uncommonly these days the SOAD will consider the dose to be too greatly in excess of the "BNF maximum" and approve only a lower dosage. Consequently the patient's mental state deteriorates.

For the future, my logical course of action is to use Depixol as a first choice for all my patients, in order to avoid the problem of "the BNF maximum". This does however appear somewhat therapeutically restrictive. I would thus be grateful to know the objective basis for the limits set.

ANN BARKER

Broadmoor Hospital

Crowthorne, Berkshire

RG11 7EG

The President set up a consensus group under my chairmanship on 14 December 1992 to consider the issue of high dose antipsychotic prescribing. The College is taking this seriously and a report is due out shortly.

Professor Chris ThOMPson 